\title{
Article \\ Cytotoxicity of Aspergillus Section Fumigati Isolates Recovered from Protection Devices Used on Waste Sorting Industry
}

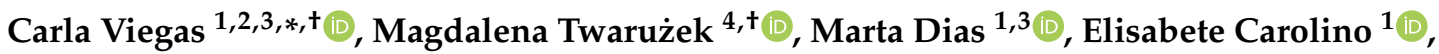 \\ Ewelina Soszczyńska ${ }^{4}$ (I) and Liliana Aranha Caetano ${ }^{1,5}$ (D)
}

1 H\&TRC—Health \& Technology Research Center, ESTeSL-Escola Superior de Tecnologia da Saúde, Instituto Politécnico de Lisboa, 1990-096 Lisbon, Portugal; martasfd@gmail.com (M.D.); etcarolino@estesl.ipl.pt (E.C.); liliana.caetano@estesl.ipl.pt (L.A.C.)

2 NOVA National School of Public Health, Public Health Research Centre, Universidade NOVA de Lisboa, 1099-085 Lisbon, Portugal

3 Comprehensive Health Research Center (CHRC), NOVA Medical School, Universidade NOVA de Lisboa, 1169-056 Lisbon, Portugal

4 Department of Physiology and Toxicology, Faculty of Biological Sciences, Kazimierz Wielki University, Chodkiewicza 30, 85-064 Bydgoszcz, Poland; twarmag@ukw.edu.pl (M.T.); eweso@ukw.edu.pl (E.S.)

5 Research Institute for Medicines (iMed.ULisboa), Faculty of Pharmacy, University of Lisbon, 1649-003 Lisbon, Portugal

* Correspondence: carla.viegas@estesl.ipl.pt

+ These authors contributed equally to this work.

\section{check for} updates

Citation: Viegas, C.; Twarużek, M.; Dias, M.; Carolino, E.; Soszczyńska, E.; Aranha Caetano, L. Cytotoxicity of Aspergillus Section Fumigati Isolates Recovered from Protection Devices Used on Waste Sorting Industry. Toxins 2022, 14, 70. https:// doi.org/10.3390/toxins 14020070

Received: 12 November 2021

Accepted: 14 January 2022

Published: 20 January 2022

Publisher's Note: MDPI stays neutral with regard to jurisdictional claims in published maps and institutional affiliations.

Copyright: (๑) 2022 by the authors Licensee MDPI, Basel, Switzerland. This article is an open access article distributed under the terms and conditions of the Creative Commons Attribution (CC BY) license (https:// creativecommons.org/licenses/by/ $4.0 /)$.

\begin{abstract}
Safe working conditions must be guaranteed during waste sorting, which is crucial to maximizing recycling and reuse, in order to minimize workers' exposure to chemical and biological hazards. This study determines the contribution of Aspergillus section Fumigati to the overall cytotoxicity of filtering respiratory protection devices (FRPD) and mechanic protection gloves (MPG) collected in 2019 from different workstations in one waste sorting industry in Portugal. The cytotoxicity of 133 Aspergillus section Fumigati isolates was determined as IC50 in human A549 epithelial lung cells and swine kidney cells, using the MTT (3-(4,5-dimethylthiazol-2-yl)-2,5-diphenyltetrazolium bromide) assay. Aspergillus section Fumigati cytotoxicity results were compared with previous total cytotoxicity data from FRPD and MPG samples. A significant correlation was detected between the total cytotoxicity of samples and cytotoxicity of Aspergillus section Fumigati isolates in A549 cells $(\mathrm{rS}=-0.339, p=0.030)$. The cytotoxicity of Aspergillus section Fumigati isolates explained $10.7 \%$ of the total cytotoxicity of the sample. On the basis of the comparison of cytotoxicity levels, it was possible to determine the contribution of Aspergillus section Fumigati isolates for the total cytotoxicity of protection devices used in the waste sorting industry. The results support in vitro toxicology as a relevant approach in risk assessments regarding cytotoxicity in passive sampling, and thus, useful in determining the contribution of relevant microbial contaminants to overall cytotoxicity. This approach can provide valuable answers in dose/response studies, and support innovations in risk characterization and their translation into occupational policies.
\end{abstract}

Keywords: cytotoxicity; protection devices; MTT assay; risk assessment; waste sorting environment

Key Contribution: The cytotoxicity of Aspergillus section Fumigati isolates explained $10.7 \%$ of the total cytotoxicity of the sample. The results support in vitro toxicology as a relevant approach in risk assessments.

\section{Introduction}

European countries have established a reduction in the amount of waste produced to ensure full implementation of the waste policy targets in all member states [1]. Additionally, a circular economy increases waste recovery and thus, leads to a great workforce engaged in waste management. Waste sorting industries are one of the key points to achieving the 
European Union milestones and Sustainable Development Goals (SDGs) proposed by the World Health Organization. It is crucial to raise waste sorting to maximize recycling and reuse and, in parallel, to ensure safe working conditions. Therefore, although improved waste management contributes to reducing environmental negative impacts and health outcomes, the exposure of workers in waste sorting to microorganisms may increase, leading to a negative impact on workers' health.

It has been reported that workers in waste sorting plants (WSP) are exposed to a complex mixture of contaminants of chemical and biological origin [2-5]. These mixtures of contaminants, difficult to entirely characterize, are most certainly responsible for biological responses that can result in health disorders [6-8]. Despite information on health outcomes obtained from epidemiological studies, these are not enough to establish a link between exposure and health problems, leading to the unavailability of occupational exposure limit values (OELs) for airborne biological agents [9]. The health outcomes caused by exposure to bioaerosols are linked to the specific microorganisms to which workers are exposed. Therefore, it is extremely important to characterize very well the toxigenic potential of each microorganism.

Aspergillus section Fumigati (one section of the Aspergillus genus) was reported as one of the most prevalent fungal species in filtering respiratory protection devices (FRPD) and mechanic protection gloves (MPG) $[10,11]$, as in other environmental samples $[4,7]$, from the same waste sorting unit. Moreso, the Fumigati section was the most abundant Aspergillus section detected on the interior layers (IL) (33.33\%, 40 samples out of 120) and on the exhalation valves (EV) (1.66\%, 2 samples out of 120) of FRPD [10]. Regarding MPG, the Fumigati section was the second most prevalent among the Aspergillus genus on DG18 $(23.17 \%)$ [11].

Aspergillus section Fumigati is the Aspergillus section more often associated with respiratory symptoms due to the small size of the conidia and other virulence factors [12,13]. Of note, the development of resistance to antifungal drugs among Aspergillus sections, mainly in section Fumigati, is a phenomenon with growing prevalence in Europe that has been related to therapeutic failure and high mortality rates, mostly due to opportunistic invasive fungal infections among immunocompromised individuals [14].

Although it is generally accepted that fungal exposure is unhealthy, and measures must be taken to limit fungi development, the available literature on adverse health effects from exposure to airborne toxigenic fungi is scarce or lacks clarity in establishing the link between exposure and the observed biological effects. Long-term exposure to toxigenic fungi has been suggested as being disruptive of natural killer cell activity, causing symptoms such as headaches, fever, cough, depression, anxiety, among others [15]. Other studies reported exposure to fungi and bioaerosols as inducers of immunosuppression and inflammation [16,17].

Without weakening the features of molecular analysis, culture-based methods are still critical to assess the viability of pathogenic microorganisms related to their infectivity potential. Furthermore, a microorganism's viability is associated with the potential of inflammatory and cytotoxic responses and, consequently, the infection potential. Therefore, molecular tools must be used in parallel with classic methods [18-20]. In addition, in exposure assessment studies, where the exposure is mainly occurring by inhalation, the outcomes of respiratory diseases may vary significantly with fungal viability, and thus, it is of utmost importance to apply cultures for the fungal assessment or isolates recovery [21]. This corroborates the importance to perform the identification by culture, using the same procedure as in clinical samples, since it is the gold standard for the diagnosis of fungal infections and allows susceptibility testing [22,23].

In the current study, the contribution of Fumigati isolates from the Aspergillus section to the cytotoxicity of FRPD and MPG samples from the waste sorting industry was determined. The research is part of a wider project consisting of a multi-faceted pilot study aiming to analyze the cytotoxicity of protection devices used in the waste sorting industry. In this study, the cytotoxicity of Fumigati isolates was determined as IC50 in two different 
mammalian cell lines using the 3-(4,5-dimethylthiazol-2-yl)-2,5-diphenyltetrazolium bromide (MTT) assay and were compared to previous results obtained with composite FRPD and MPG samples. In addition, a detailed statistical analysis was conducted with the aim of evaluating the relations between the cytotoxic effect of Fumigati isolates and the total cytotoxicity of the FRPD and MPG samples.

\section{Materials and Methods}

\subsection{Protection Devices' Sampling and Sample Preparation}

The sampling of protection devices was the same as Viegas et al. 2020 [10,11]. Briefly, over 180 protection devices used by waste workers (namely, FRPD $(\mathrm{N}=120)$ and MPG $(\mathrm{N}=67)$ ) were randomly collected on a weekday during the winter season (between January and February 2019) in four workstations (Table S1-Supplementary Material) at one waste sorting industry located in Lisbon, Portugal. Samples were kept refrigerated and processed in aseptic conditions, as previously reported $[10,11]$, and characterized regarding their microbial contamination and cytotoxic effect $[10,11,24]$.

\subsection{Microbiological Characterization and Cytotoxicity Evaluation of FRPD e MPG}

Selective culture media for fungi were used to allow fungal growth (malt extract agar (MEA) supplemented with chloramphenicol (0.05\%); dichloran-glycerol agar (DG18)) and to screen azole resistance (Sabouraud dextrose agar (SDA) supplemented with $4 \mathrm{mg} / \mathrm{L}$ itraconazole (ITR), $1 \mathrm{mg} / \mathrm{L}$ voriconazole (VOR), $0.5 \mathrm{mg} / \mathrm{L}$ posaconazole (POS), or nonsupplemented (adapted from EUCAST 2018)). FRPD and MPG, without prior use, were used as negative controls. All samples were characterized regarding fungal contamination (fungi colony-forming units, CFU.m ${ }^{-2}$ ) and diversity (morphological characterization and molecular detection) [10,11]. Microscopic mounts were performed using a tease mount or Scotch tape mount and lactophenol cotton blue mount procedures, and the morphological identification from all of the fungi was performed using macro- and microscopic characteristics, as reported before [10,11].

\subsection{Collection of Aspergillus Section Fumigati Isolates}

Aspergillus section Fumigati isolates were extracted from each FRPD-IL, EV and MPG sample after its identification in at least one media (MEA, DG18, SDA, or azolesupplemented SDA). Only one isolate from one media per sample was used. We selected the one with a higher possibility to obtain a pure culture of the Fumigati isolate without contamination, following the procedures already published [25] (Figure 1).

A total of 133 isolates from Aspergillus section Fumigati were recovered. Considering each matrix, the one with the highest prevalence of isolates was the IL from the FRPD (FRPD-IL) with a total of 61 isolates, followed by the 50 isolates from EV (FRPD-EV).

The media with the highest number of isolates was MEA, with a total of 53 isolates, followed by SAB with a total of 48 isolates. It is important to highlight that there were 4 isolates recovered ( 2 from FRPD-IL; 2 from FRPD-EV) growing on ITR, and 2 isolates from FRPD-IL growing on VOR. No isolates were recovered from POS (Table 1).

Table 1. The number of Aspergillus section Fumigati isolates recovered from different sources per culture media.

\begin{tabular}{cccccccc}
\hline Source & MEA & DG18 & SAB & ITR & VOR & POS & Total \\
\hline FRPD-IL & 24 & 11 & 22 & 2 & 2 & 0 & 61 \\
FRPD-EV & 21 & 14 & 13 & 2 & 0 & 0 & 50 \\
MPG & 8 & 1 & 13 & 0 & 0 & 0 & 22 \\
TOTAL & 53 & 26 & 48 & 4 & 2 & 0 & 133 \\
\hline
\end{tabular}




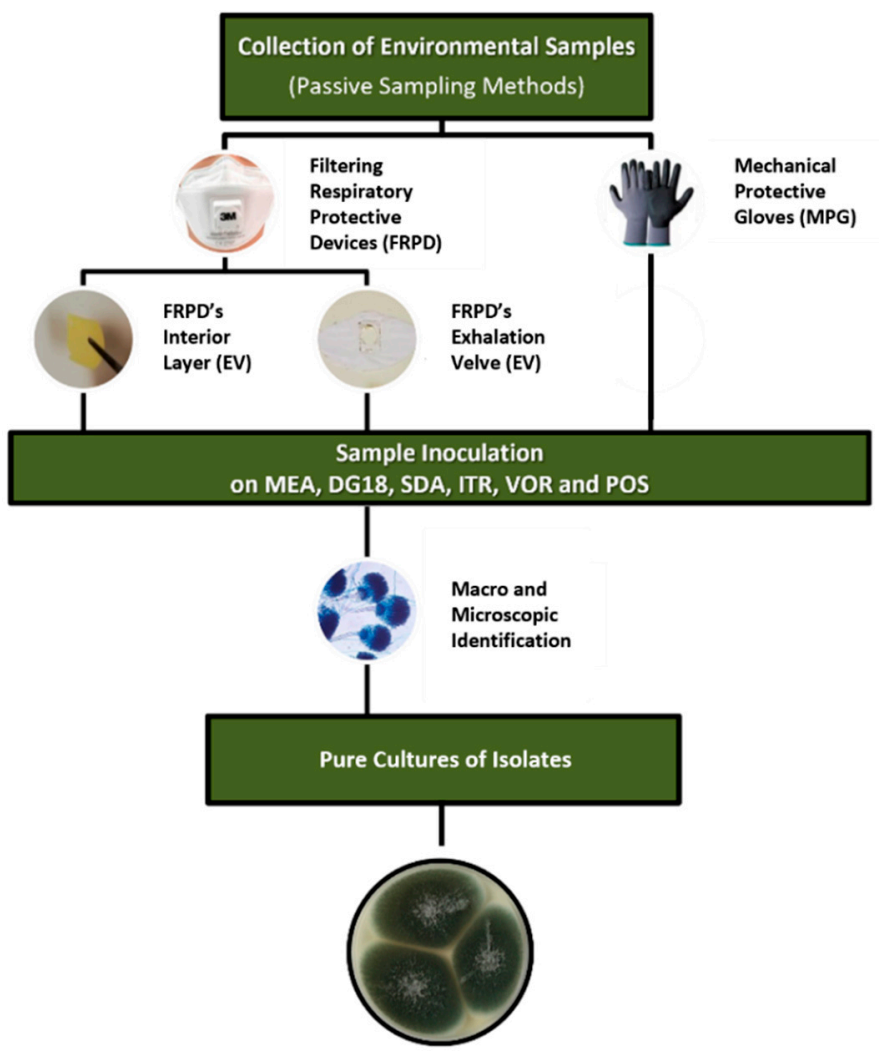

Figure 1. Protocol applied for the Aspergillus section Fumigati isolates collection.

\subsection{Cell Lines and Culture Conditions}

Two mammalian cell lines were used to screen the cytotoxicity of the Aspergillus section Fumigati isolates. Swine kidney (SK) cells, derived from a cell culture collection of the Ludwig-Maximilians-Universität München, were kindly provided by Prof. Manfred Gareis, Ph.D., in 2011. Human A549 epithelial lung cells were purchased from the ATCC collection. The cells were maintained in Eagle's Minimum Essential Medium (MEM) supplemented with 10,000 units of penicillin and $10 \mathrm{mg}$ of streptomycin per $\mathrm{mL}$ in $0.9 \% \mathrm{NaCl}$ (SigmaAldrich, St. Louis, MO, USA) and fetal bovine serum (Sigma-Aldrich, St. Louis, MO, USA).

\subsection{Cytotoxicity Evaluation}

Extracts containing an equivalent of Aspergillus section Fumigati grown on one $62.5 \mathrm{~cm}^{2}$ surface Petri dish were prepared as follows: colonies of the fungi were grown on Czapek Dox agar at $25{ }^{\circ} \mathrm{C}$ for 2 weeks, and the following 2 weeks in $10{ }^{\circ} \mathrm{C}$. Then, colonies of Aspergillus section Fumigati were removed from Petri dishes with a sterile scalpel and transferred to a sterile bag (BagLight ${ }^{\circledR}$, Interscience, Dubai, Emirates United States). Then, $50 \mathrm{~mL}$ of chloroform was added and homogenized for $5 \mathrm{~min}$ in a laboratory blender (BagMixer 400, Interscience). The mycelium was harvested by filtration through Whatman filter paper. The samples were evaporated to dryness. The received extracts were dissolved in $1 \mathrm{~mL}$ of mixture of ethanol dimethyl sulfoxide-minimum essential medium with Earle's salts $(\mathrm{MEM})(1.7+0.3+98, v / v / v$. Then, serial $\log 2$ dilutions of the sample extract were prepared.

The A549 and SK cells were used to evaluate the cytotoxic effect of Aspergillus section Fumigati isolates. The cell cultures were harvested using $0.25 \%(w / v)$ Trypsin $0.53 \mathrm{mM}$ EDTA, suspended in the culture medium. After cell count using the Scepter TM 2.0 Cell Counter (Merck), A549 and SK cells were transferred (100 $\mu \mathrm{L})$ to a 96 -well plate (densities of $2.5 \times 10^{5}$ cells $/ \mathrm{mL}$ ) and exposed to serial $\log 2$ dilutions of sample extracts for $48 \mathrm{~h}$ at $5 \%$ $\mathrm{CO}_{2}, 37^{\circ} \mathrm{C}$, and humid atmosphere. The cytotoxicity level was measured by reduction of MTT tetrazolium salt to formazan at $510 \mathrm{~nm}$ [26] (ELISA LEDETECT 96, BioMed Dr. Wieser 
$\mathrm{GmbH}$; MikroWin 2013SC software). The lowest concentration of sample extracts causing a drop in absorption to $<50 \%$ of cell division activity (IC50) was considered the threshold toxicity level.

\subsection{Statistical Analysis}

The data were analyzed using the statistical software SPSS V26.0 for windows. The results were considered significant at the 5\% significance level. To test the normality of the data, the Shapiro-Wilk test was used. For the comparison of the IC50 values both in the sample and in the Aspergillus section Fumigati isolates between the sample type (FRPD-IL and EV; MPG) and between the media, the Kruskal-Wallis test was used since the assumption of normality was not verified. To study the relationship between the IC50 values of A549 and SK cells between the sample and the Aspergillus section Fumigati isolates, Spearman's correlation coefficient was used. To evaluate the influence of the values of the Aspergillus section Fumigati isolates on the sample values, simple linear regression analysis was used, with the model checking the Gauss-Markov conditions.

\section{Results}

\subsection{Aspergillus Section Fumigati Cytotoxicity}

Aspergillus section Fumigati was screened for cytotoxicity in A549 and SK cells, in order to determine their contribution to the overall cytotoxic effect previously observed in FRPD (IL and EV) and MPG samples (Supplementary Material-Tables S1-S4). The obtained results are presented in Table 2. An example of Aspergillus section Fumigati sample extracts' cytotoxicity is presented in Figure 2a,b.

Table 2. Frequencies of threshold toxicity level (IC50) of Aspergillus section Fumigati.

\begin{tabular}{cccc}
\hline \multirow{2}{*}{ Dilution Step } & IC50 & A549 & SK \\
\cline { 2 - 4 } & & $\boldsymbol{N}$ & $\boldsymbol{N}$ \\
\hline 1 & $31.250 \mathrm{~cm}^{2} / \mathrm{mL}$ & 1 & 2 \\
2 & $15.625 \mathrm{~cm}^{2} / \mathrm{mL}$ & 1 & 2 \\
3 & $7.813 \mathrm{~cm}^{2} / \mathrm{mL}$ & 4 & 3 \\
4 & $3.906 \mathrm{~cm}^{2} / \mathrm{mL}$ & 1 & 3 \\
5 & $1.953 \mathrm{~cm}^{2} / \mathrm{mL}$ & 0 & 3 \\
6 & $0.977 \mathrm{~cm}^{2} / \mathrm{mL}$ & 2 & 6 \\
7 & $0.488 \mathrm{~cm}^{2} / \mathrm{mL}$ & 3 & 11 \\
8 & $0.244 \mathrm{~cm}^{2} / \mathrm{mL}$ & 4 & 20 \\
9 & $0.122 \mathrm{~cm}^{2} / \mathrm{mL}$ & 27 & 31 \\
10 & $0.061 \mathrm{~cm}^{2} / \mathrm{mL}$ & 48 & 52 \\
11 & $3.050 \mathrm{~mm}^{2} / \mathrm{mL}$ & 25 & 0 \\
12 & $1.525 \mathrm{~mm}^{2} / \mathrm{mL}$ & 10 & 0 \\
13 & $0.7625 \mathrm{~mm}^{2} / \mathrm{mL}$ & 3 & 0 \\
14 & $0.3812 \mathrm{~mm}^{2} / \mathrm{mL}$ & 2 & 0 \\
15 & $0.1906 \mathrm{~mm}^{2} / \mathrm{mL}$ & 1 & 0 \\
16 & $0.0953 \mathrm{~mm}^{2} / \mathrm{mL}$ & 1 & \\
\hline
\end{tabular}

The source of fungi (FRPD-IL, FRPD-EV or MPG) had no statistically significant differences for IC50 in A549 cells $\left(\chi^{2}(2)=0.906, p=0.636\right)$ or SK cells $\left(\chi^{2}(2)=2.979\right.$, $p=0.225)$. A statistically significant lower cytotoxic effect was detected for Aspergillus section Fumigati grown on ITR media in SK cells $\left(\chi^{2}(2)=8058, p=0.045\right)$. 


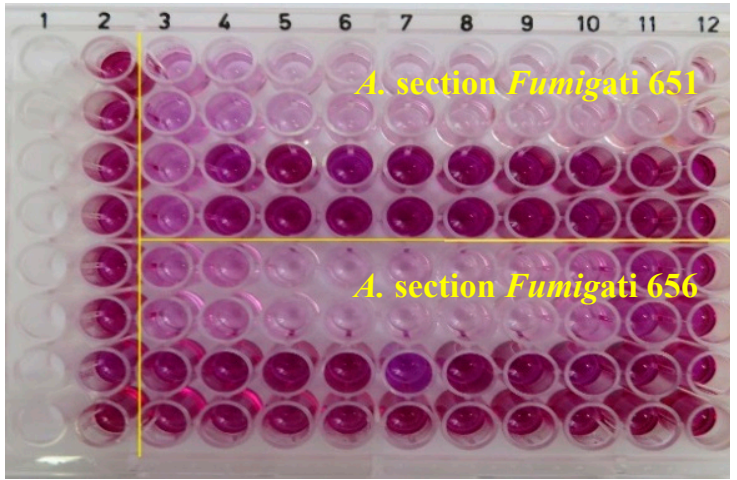

(a)

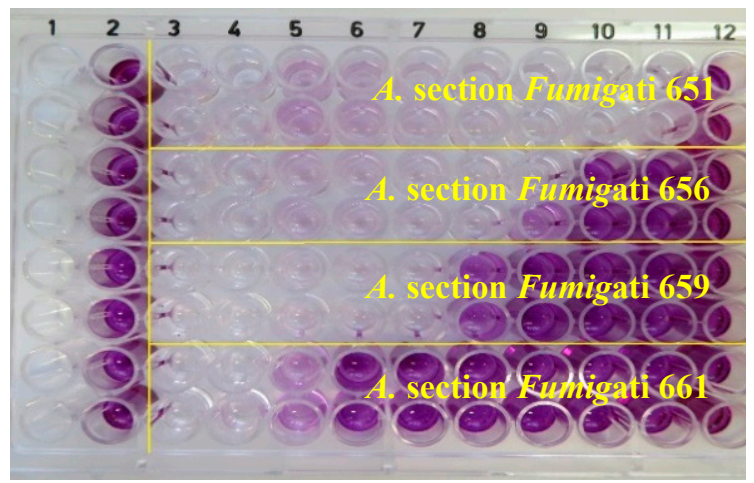

(b)

Figure 2. Photographs of the MTT micro-plates with extracts containing the Aspergillus section Fumigati recovered from SAB media (651, 656, and 659) and from ITR medium (661): (a) A549 cells; (b) SK cells.

\subsection{Correlation Analysis}

In A549 cells, there was a significant and inverse correlation between whole sample IC50 values and Aspergillus section Fumigati isolates IC50 values (rS $=-0.339, p=0.030$ ), indicating that greater IC50 of Aspergillus section Fumigati isolates was associated with lower IC50 of the whole sample (Table 3). These findings reveal that Aspergillus section Fumigati isolates account for just $10.7 \%$ of the cytotoxicity found in the whole sample from which it was recovered, implying that other components of the sample account for the remaining $89.3 \%$.

Table 3. Study of the relationship between IC50 A549 and SK cells between the sample and the Aspergillus section Fumigati isolates. Spearman correlation results.

\begin{tabular}{ccccc}
\hline & & $\begin{array}{c}\text { IC50 in the } \\
\text { Sample }\end{array}$ & \multicolumn{2}{c}{$\begin{array}{c}\text { IC50 Aspergillus Section } \\
\text { Fumigati Isolates }\end{array}$} \\
\cline { 2 - 5 } & & SK & A549 & SK \\
\hline IC50 in the sample & A549 & 0.667 & $-0.339 *$ & -0.157 \\
IC50 Aspergillus section & SK & & 0.247 & -0.128 \\
Fumigati isolates & A549 & & & 0.076 \\
\hline
\end{tabular}

* Correlation is significant at the 0.05 level (2-tailed).

\section{Discussion}

Bioassays to assess the toxicity of microorganisms present at workplaces enable the identification of risk factors for workers' health. Current trends in European policies dedicated to waste management, fostered by the implementation of the Sustainable Development Goals worldwide, reinforce this endeavor as of critical importance, due to the increase in the workforce engaged in waste sorting. The characterization of the toxigenic potential of microorganisms present in the waste sorting workplaces is, however, a major challenge. This assessment includes air sampling and passive sampling, and might include individual protection devices $[11,24]$.

The choice of appropriate cell lines is critical when conducting bioassays to elucidate induced toxicity in humans. The human A549 epithelial lung cell line is largely used in lung cell biology [27] and was applied in this study as a model for alveolar cells, while the swine kidney (SK) cells are a valid alternative to primary human cells for renal in vitro toxicology, due to high similarity in renal physiology [28]. The 3-[4,5, dimethylthiazol-2-yl]2-5 diphenyltetrazolium (MTT) tetrazolium salt assay has commonly been used to measure cytotoxicity in different cell lines, comprising cell lines of animal and human origin [7,29] and indicates cell respiration competence and metabolic activity. Prinsloo and colleagues 
have already used the MTT assay to determine the effect of microbial contaminants on cell viability [30].

Based on biological responses obtained from the mycobiota assessment in the environment, such as cytotoxicity or inflammasome, conclusions about potential health risks following specific exposure routes can be drawn. Aside from more common mycotoxins' assessments, other fungal substances, such as cytoplasmatic and cell wall components, can be released into the environment by fungal hyphae and exert noxious health effects [31,32]. Fungal cytotoxicity, determined by in vitro evaluation of fungal contaminated building materials, has been reported to be linked to the quality and quantity of mycotoxigenic fungi, rather than with mycotoxins alone [33]. The cytotoxicity of fungal extracts is further confirmed by other studies, which concluded that fungal extracts exerted a cytotoxic effect and presented a potential health risk following exposure by inhalation of fungal spores of common indoor molds [34]. Of note, while the exposure to airborne fungal might predispose to fungal colonization of the airways without infection [35], it is a relevant risk factor for infection in more sensitive individuals, such as workers suffering from asthma.

Recent studies from our group assessing the cytotoxic effect of contamination present in MPG and in FRPD used in the waste sorting, also revealed a cytotoxic effect of both in mammalian cell lines, being higher in MPG than in FRPD in SK cells [36]. This might be related to the time of use. Moreso, MPG were used in more than one work shift, while FRPD were replaced in each work shift, thus, justifying the higher cytotoxicity observed in SK cells. Indeed, the number of hours of use was found to be positively correlated with microbial contamination found on MPG and SK cells [11].

In the present study, the Aspergillus section Fumigati recovered from the whole FRPD and MPD samples were screened for cytotoxicity in A549 and SK cells using the MTT assay to elucidate the contribution of this fungal species for overall cytotoxicity. It was observed that the cytotoxicity of Aspergillus section Fumigati contributed only $10.7 \%$ to the cytotoxicity of the whole sample. The cytotoxicity of the whole sample might be related to a wide array of contaminants and pollutants that are common in the waste sorting industry [37]. Aside from organic contaminants, inorganic components (not analyzed in this study), such as metals (lead and chromium), persistent organic pollutants (polycyclic aromatic hydrocarbons (PAHs)), bisphenols, phthalates, and brominated flame retardants that originate from the residues sorted in the waste sorting unit, might also be present and have a cytotoxic effect, particularly in lung cells [38]. Moreso, a critical aspect of the waste sorting occupational environment is that workers are exposed to a complex mixture of chemical and biological contaminants which complete characterization, though urgent, is difficult to achieve with standard sampling methods and reproducible data $[7,8]$. This aspect may explain the contribution of only $10.7 \%$ of the Fumigati section to the general cytotoxicity of the samples. However, we should consider that cytotoxicity effects found on FRPD and MPG are most likely linked to microbial contamination than chemical pollutants since high levels of chemical contaminants would cause acute toxicity among workers, whereas low chemical concentrations rarely have an effect on cell viability $[19,30]$.

A cytotoxicity evaluation of fungi belonging to genus Aspergillus collected from various hospital wards [39] concluded that Aspergillus species were cytotoxic in $79 \%$ of the cases, with significant differences in the average cytotoxicity, depending on the species (A. ochraceus, A. flavus and A. niger species), although no conclusions could be drawn on which species was more cytotoxic. These results were much higher than the previously obtained with fungal spores from humid domestic environments, in which $47 \%$ of the evaluated fungi displayed cytotoxicity in vivo [40]. Regarding cytotoxicity depending on fungal species/sections, Aspergillus section Fumigati has been reported to be more cytotoxic than other Aspergillus sections [41,42]. Some bioactive fungal compounds from Aspergillus species have been described as presenting cytotoxicity, namely, bisabolone sesquiterpenoid derivatives isolated from Aspergillus tennesseensis [43]. Some of these compounds were described to present cytotoxicity against A549 cells with IC50 ranging from 44 to $61 \mu \mathrm{M}$ [43]. 
In future studies, to compare the cytotoxicity between different Fumigati isolates, genetic characterization from isolates will be ensured $[25,44]$.

Additional assays or the use of additional cell lines and other biomarkers will be important to better estimate the cytotoxicity of Aspergillus section Fumigati isolates. Furthermore, in vitro toxicology should always be combined with an accurate assessment of exposure to microbial and chemical contamination. This should be the followed approach to achieve useful information on the potential health effects of co-exposure to multiple stressors [24].

In order to fill the data gaps of concern for regulatory authorities (risk assessors and/or risk managers), toxicological studies need to be developed for the assessment (in vitro) of mixtures relevant to occupational health. Due to the lack of information on all the risk factors that are present in waste sorting plants [2-5], that are deeply dependent on the kind of waste that is being sorted, and the difficulty to accurately assess the exposure to all the pollutants, it is critical to perform the overall cytotoxicity from the sample extracts as a cytotoxicity pre-screening, as was the case of the previous studies performed to FRPD and MPG [11,24]. After identifying the potential indicators of each kind of pollutants-Aspergillus section Fumigati for mycological contamination-the assessment of their own contribution to the overall cytotoxicity might help to unveil potential health risks of exposure.

\section{Conclusions}

This study made it possible to determine the contribution of isolates from the Aspergillus section Fumigati to the total cytotoxicity of the protection devices analyzed. These results support in vitro toxicology as a suitable approach to follow in risk assessments in settings with a high burden of microbial contamination, such as waste sorting occupational environment as follows: first, screening of the overall cytotoxicity of passive samples; and second, to assess the contribution of relevant indicators for each group of pollutants (microbial, chemical) to general cytotoxicity. This approach of focusing on in vitro toxicology can provide valuable answers in dose/response studies, and support innovations in risk characterization and their translation into occupational policies.

Supplementary Materials: The following are available online at https:/ /www.mdpi.com/article/10 .3390 / toxins14020070/s1, Table S1: IC50 values ( $\mathrm{mm}^{2} / \mathrm{mL}$ ) of FRPD, per workstation, determined by the dilution method in A549 and SK cells (MTT assay); Table S2: IC50 values $\left(\mathrm{mm}^{2} / \mathrm{mL}\right)$ of gloves, determined by the dilution method in HepG2 and SK cells (MTT assay); Table S3: Heatmap for IC50 values $\left(\mathrm{mm}^{2} / \mathrm{mL}\right)$ in the sample from FRPD and MPG, determined by the dilution method in A549 and SK cells (MTT assay); Table S4: Heatmap for IC50 values $(\mathrm{mm} 2 / \mathrm{mL})$ in the sample from FRPD and MPG, determined by the dilution method in A549 and SK cells (MTT assay).

Author Contributions: Conceptualization, C.V.; methodology, C.V., M.T. and L.A.C.; formal analysis, M.D., E.C. and E.S.; investigation, C.V., M.T. and L.A.C.; resources, C.V. and M.T.; writing-original draft preparation, C.V., M.T. and L.A.C.; writing-review and editing, C.V. and L.A.C.; supervision, C.V. and M.T.; project administration, C.V.; funding acquisition, C.V. and M.T. All authors have read and agreed to the published version of the manuscript.

Funding: This research was funded by FCT—Fundação para a Ciência e a Tecnologia, I.P. (Portugal) for funding the EEA Grants Project "EXPO-Green", by Instituto Politécnico de Lisboa, Lisbon, Portugal for funding the Project "Waste Workers' Exposure to Bioburden through Filtering Respiratory Protective Devices" (IPL/2018/WasteFRPD_ESTeSL) and to Polish Minister of Science and Higher Education, under the program "Regional Initiative of Excellence" in 2019-2022 (Grant No. 008/RID/2018/19). This project was also supported by FCT/MCTES (UIDB/05608/2020 and $\mathrm{UIDP} / 05608 / 2020)$.

Institutional Review Board Statement: Not applicable.

Informed Consent Statement: Not applicable.

Conflicts of Interest: The authors declare no conflict of interest. 


\section{References}

1. European Union. DIRECTIVE 2008/98/EC of the European Parliament and of the Council. 2008. Available online: https: / / eur-lex.europa.eu/legal-content/EN/ALL/?uri=CELEX\%3A32008L0098 (accessed on 5 January 2022).

2. Park, D.U.; Ryu, S.H.; Kim, S.-B.; Yoon, C.-S. An assessment of dust, endotoxin, and microorganism exposure during waste collection and sorting. J. Air Waste Manag. Assoc. 2011, 61, 461-468. [CrossRef]

3. Schlosser, O.; Déportes, I.Z.; Facon, B.; Fromont, E. Extension of the sorting instructions for household plastic packaging and changes in exposure to bioaerosols at materials recovery facilities. Waste Manag. 2015, 46, 47-55. [CrossRef] [PubMed]

4. Viegas, C.; Faria, T.; dos Santos, M.; Carolino, E.; Gomes, A.Q.; Sabino, R.; Viegas, S. Fungal burden in waste industry: An occupational risk to be solved. Environ. Monit. Assess. 2015, 187, 199. [CrossRef] [PubMed]

5. Madsen, A.M.; Frederiksen, M.W.; Jacobsen, M.H.; Tendal, K. Towards a risk evaluation of workers' exposure to handborne and airborne microbial species as exemplified with waste collection workers. Environ. Res. 2020, 183, 109177. [CrossRef]

6. Poole, C.J.M.; Basu, S. Systematic Review: Occupational illness in the waste and recycling sector. Occup. Med. 2017, 67, 626-636. [CrossRef]

7. Viegas, S.; Caetano, L.A.; Korkalainen, M.; Faria, T.; Pacífico, C.; Carolino, E.; Quintal Gomes, A.; Viegas, C. Cytotoxic and Inflammatory Potential of Air Samples from Occupational Settings with Exposure to Organic Dust. Toxics 2017, 5, 8. [CrossRef]

8. Ladeira, C.; Gajski, G.; Meneses, M.; Gerić, M.; Viegas, S. The genotoxicity of an organic solvent mixture: A human biomonitoring study and translation of a real-scenario exposure to in vitro. Regul. Toxic. Pharmacol. 2020, 116, 104726. [CrossRef] [PubMed]

9. Degois, J.; Simon, X.; Clerc, F.; Bontemps, C.; Leblond, P.; Duquenne, P. One-year follow-up of microbial diversity in bioaerosols emitted in a waste sorting plant in France. Waste Manag 2021, 120, 257-268. [CrossRef] [PubMed]

10. Viegas, C.; Dias, M.; Almeida, B.; Aranha Caetano, L.; Carolino, E.; Quintal Gomes, A.; Twaruzek, M.; Kosicki, R.; Grajewski, J.; Marchand, G.; et al. Are workers from waste sorting industry really protected by wearing Filtering Respiratory Protective Devices? The gap between the myth and reality. Waste Manag. 2020, 102, 856-867. [CrossRef]

11. Viegas, C.; Twarużek, M.; Dias, M.; Almeida, B.; Carolino, E.; Kosicki, R.; Soszczyńska, E.; Grajewski, J.; Aranha Caetano, L.; Viegas, S. Assessment of the microbial contamination of mechanical protection gloves used on waste sorting industry: A contribution for the risk characterization. Environ. Res. 2020, 189, 109881. [CrossRef]

12. Varga, J.; Baranyi, N.; Chandrasekaran, M.; Vágvölgyi, C.; Kocsubé, S. Mycotoxin producers in the Aspergillus genus: An update. Acta Biol. Szeged. 2015, 59, 151-167.

13. Sabino, R. Exposure to Fungi in Health Care Facilities. In Encyclopedia of Mycology; Zaragoza, O., Casadevall, A., Balestrini, R., Nosanchuk, J., Viegas, C., Vizzini, A., de Vries, R., Eds.; Elsevier: Amsterdam, The Netherlands, 2021. [CrossRef]

14. Nature Microbiology. Stop neglecting fungi. Nat. Microbiol. 2017, 2, 17120. [CrossRef]

15. Anyanwu, E.C.; Campbell, A.W.; Jones, J.; Ehiri, J. The neurological significance of abnormal natural killer cell activity in chronic toxigenic mold exposures. Scien. World J. 2003, 13, 1128-1137. [CrossRef] [PubMed]

16. Sutton, P.; Newcombe, N.R.; Waring, P.; Müllbacher, A. In vivo immunosuppressive activity of gliotoxin, a metabolite produced by human pathogenic fungi. Infect. Immun. 2003, 62, 1192-1198. [CrossRef] [PubMed]

17. Cramer, R.A.; Rivera, A.; Hohl, T.M. Immune responses against Aspergillus fumigatus: What have we learned? Curr. Opin. Infect. Dis. 2011, 24, 315-322. [CrossRef]

18. Viegas, C.; Caetano, L.A.; Viegas, S. Occupational Exposure to Aspergillus Section Fumigati: Tackling the Knowledge Gap in Portugal. Environ. Res. 2021, 194, 110674. [CrossRef]

19. Yoo, K.; Lee, T.K.; Choi, E.J.; Yang, J.; Shukla, S.K.; Hwang, S.-I.; Park, J. Molecular Approaches for the Detection and Monitoring of Microbial Communities in Bioaerosols: A Review. J. Environ. Sci. 2017, 51, 234-247. [CrossRef]

20. Viegas, C.; Gomes, B.; Dias, M.; Carolino, E.; Aranha Caetano, L. Aspergillus Section Fumigati in Firefighter Headquarters. Microorganisms 2021, 9, 2112. [CrossRef]

21. Pandey, S.; Hoselton, S.A.; Schuh, J.M. The Impact of Aspergillus Fumigatus Viability and Sensitization to Its Allergens on the Murine Allergic Asthma Phenotype. BioMed Res. Int. 2013, 619614. [CrossRef]

22. Clinical \& Laboratory Standards Institute: CLSI Guidelines. Available online: https:/ / clsi.org/ (accessed on 5 January 2022).

23. Kozel, T.R.; Wickes, B. Fungal Diagnostics. Cold Spring Harb. Perspect. Med. 2014, 4, a019299. [CrossRef] [PubMed]

24. Viegas, C.; Twarużekd, M.; Dias, M.; Almeida, B.; Carolino, E.; Soszczyńska, E.; Viegas, S.; Caetano, L.A. Cytotoxicity of filtering respiratory protective devices from the waste sorting industry: A comparative study between interior layer and exhalation valve. Environ. Inter. 2021, 155, 106603. [CrossRef]

25. Viegas, C.; Almeida, B.; Aranha Caetano, L.; Afanou, A.; Straumfors, A.; Veríssimo, C.; Gonçalves, P.; Sabino, R. Algorithm to assess the presence of Aspergillus fumigatus resistant strains: The case of Norwegian sawmills. Inter. J. Environ. Health Res. 2020. [CrossRef]

26. Cetin, Y.; Bullerman, L.B. Cytotoxicity of Fusarium mycotoxins to mammalian cell cultures as determined by the MTT bioassay. Food Chem Toxicol. 2005, 43, 755-764. [CrossRef] [PubMed]

27. Swain, R.J.; Kemp, S.J.; Goldstraw, P.; Tetley, T.D.; Stevens, M.M. Assessment of Cell Line Models of Primary Human Cells by Raman Spectral Phenotyping. Biophys. J. 2010, 98, 1703-1711. [CrossRef]

28. Heussner, A.H.; Dietrich, D.R. Primary porcine proximal tubular cells as an alternative to human primary renal cells in vitro: An initial characterization. BMC Cell Biol. 2013, 14, 55. [CrossRef] [PubMed] 
29. Fornelli, F.; Minervini, F.; Logrieco, A. Cytotoxicity of fungal metabolites to lepidopteran (Spodoptera frugiperda) cell line (SF-9). J. Invertebr. Pathol. 2004, 85, 74-79. [CrossRef] [PubMed]

30. Prinsloo, S.; Pieters, R.; Bezuidenhout, C.C. A cell viability assay to determine the cytotoxic effects of water contaminated by microbes. S. Afr. J. Sci. 2013, 109, 7-8. [CrossRef]

31. Liang, Y.; Zhao, W.; Xu, J.; Miler, D. Characterization of 2 related exoantigens from the biodeteriogenic fungus Aspergillus versicolor. Int. Biodeterior Biodegrad. 2011, 65, 217-226. [CrossRef]

32. Ostrosky-Zeichner, L.; Alexander, B.D.; Kett, D.H.; Vazquez, J.; Pappas, P.G.; Saeki, F. Multicenter clinical evaluation of the (1 $\rightarrow 3$ ) $\beta$-D-glucan assay as an aid to diagnosis of fungal infections in humans. Clin. Infect. Dis. 2005, 41, 654-659. [CrossRef]

33. Gutarowska, B. Hyphate fungi in building materials. Increase and production of mycotoxins and allergens. Sci. Bull Tech. Uni. Lodz. 2010, 1074, 1-164.

34. Schulz, T.; Senkpiel, K.; Ohgke, H. Comparison of toxicity of reference mycotoxins and spore extracts of common indoor moulds. Int. J. Hyg. Environ. Health 2004, 207, 267-277. [CrossRef]

35. Fairs, A.; Agbetile, J.; Bourne, M.; Hargadon, B.; Monteiro, W.R.; Morley, J.P. Isolation of Aspergillus fumigatus from sputum is associated with elevated airborne levels in homes of patients with asthma. Indoor Air 2013, 23, 275-284. [CrossRef]

36. Viegas, C.; Twarużek, M.; Dias, M.; Almeida, B.; Carolino, E.; Soszczyńska, E.; Ałtyn, I.; Viegas, S.; Aranha Caetano, L. Cytotoxic effect of filtering respiratory protective devices from the waste sorting industry: Is in vitro toxicology useful for risk characterization? Environ. Res. 2020, 191, 110134. [CrossRef]

37. Grant, K.; Goldizen, F.C.; Sly, P.D. Health consequences of exposure to e-waste: Asystematic review. Lancet. Glob. Heal. 2013, 1, e350-e361. [CrossRef]

38. Thakur, P.; Ganguly, R.; Dhulia, A. Occupational health hazard exposure among municipalsolid waste workers in Himachal Pradesh, India. Waste Manag. 2018, 78, 483-489. [CrossRef] [PubMed]

39. Gniadek, A.; Krzyściak, P.; Twarużek, M.; Macura, A.B. Occurrence of fungi and cytotoxicity of the species: Aspergillus ochraceus, Aspergillus niger and Aspergillus flavus isolated from the air of hospital wards. Int. J. Occup. Med. Environ. Health 2017, 30, 231-239. [CrossRef]

40. Smith, J.E.; Anderson, J.G.; Lewis, C.W.; Murad, Y.M. Cytotoxic fungal spores in the indoor atmosphere of the damp domestic environment. FEMS Microbiol. Lett. 1992, 100, 337-343. [CrossRef]

41. Gniadek, A.; Krzyściak, P.; Hawryszuk, A.; Macura, A.B.; Brzostek, T.; Składzień, J. Mycobiota of the air in hospital rooms and the fungal colonisation of tracheostomy tubes used by patients diagnosed with larynx cancer-Preliminary research. Ann. Parasitol. 2013, 59, 69-71.

42. Kamei, K.; Watanabe, A.; Nishimura, K.; Miyaji, M. Cytotoxicity of Aspergillus fumigatus culture filtrate against macrophages. Nihon Ishinkin Gakkai Zasshi 2002, 43, 37-41. [CrossRef] [PubMed]

43. Liu, L.; Liu, R.; Basnet, B.B.; Bao, L.; Han, J.; Wang, L.; Liu, H. New phenolic bisabolane sesquiterpenoid derivatives with cytotoxicity from Aspergillus tennesseensis. J. Antibiot. 2018, 71, 538-542. [CrossRef] [PubMed]

44. Gonçalves, P.; Melo, A.; Dias, M.; Almeida, B.; Caetano, L.A.; Veríssimo, C.; Viegas, C.; Sabino, R. Azole-Resistant Aspergillus fumigatus Harboring the TR34/L98H Mutation: First Report in Portugal in Environmental Samples. Microorganisms 2021, 9, 57. [CrossRef] [PubMed] 